\title{
Genetic variation and posttranslational modification of bovine k-casein: Effects on caseino-macropeptide release during renneting
}

\author{
Hanne B. Jensen, ${ }^{* 1}$ Katrine S. Pedersen, $\dagger^{1}$ Lene B. Johansen, $\ddagger$ Nina A. Poulsen, ${ }^{*}$ Mette Bakman, $\ddagger$ \\ Dereck E. W. Chatterton, $† \S$ and Lotte B. Larsen ${ }^{\star 2}$ \\ *Department of Food Science, Aarhus University, 8830 Tjele, Denmark \\ †Department of Food Science, University of Copenhagen, 1958 Frederiksberg C, Denmark \\ $\ddagger$ Arla Strategic Innovation Centre Brabrand, Arla Foods amba, 8220 Brabrand, Denmark \\ $\S$ Clinical and Experimental Nutrition, Department of Nutrition, Exercise \& Sports, University of Copenhagen, 1958 Frederiksberg C, Denmark
}

\section{ABSTRACT}

Chymosin-induced cleavage of $\kappa$-casein $(\kappa-\mathrm{CN})$ occurs during the first enzymatic phase in milk coagulation during cheese manufacturing, where the hydrophilic Cterminal peptide of $\kappa$-CN, named caseino-macropeptide $(\mathrm{CMP})$, is released into the whey. The CMP peptide is known for its rather heterogeneous composition with respect to both genetic variation and multiple posttranslational modifications, including phosphorylation and O-linked glycosylation. An approach of liquid chromatography coupled with mass spectrometry was used to investigate (1) the overall protein profile and (2) the release of various forms of CMP after addition of chymosin to individual cow milk samples from 2 breeds, Danish Jersey (DJ) and Danish HolsteinFriesian (DH). The cows were selected to represent distinct homo- and heterozygous types of the $\kappa-\mathrm{CN}$ genetic variants $\mathrm{A}, \mathrm{B}$, and $\mathrm{E}$ (i.e., genotypes $\mathrm{AA}, \mathrm{BB}$, $\mathrm{AB}, \mathrm{EE}$, and $\mathrm{AE}$ ). Initially, investigation of the protein profile showed milk with $\kappa$-CN BB exhibited the highest relative content of $\kappa-\mathrm{CN}$, whereas AE milk exhibited the lowest, and after $40 \mathrm{~min}$ of renneting $>90 \%$ of intact $\kappa-\mathrm{CN}$ was hydrolyzed by chymosin in milk representing all $\kappa$-CN genotype. By in-depth analysis of the CMP chromatographic profile, multiple CMP isoforms with 1 to 3 O-linked glycans (1-3 G) and 1 to 3 phosphate groups (1-3 P) were identified, as well as nonmodified CMP isoforms. The number of identified CMP isoforms varied to some extent between breeds (21 CMP isoforms identified in DJ, 26 CMP isoforms in $\mathrm{DH})$ and between $\kappa$ - $\mathrm{CN}$ genetic variants (CMP variant A being the most heterogeneous compared with CMP $\mathrm{B}$ and $\mathrm{E}$ ), as well as between individual samples within each breed. The predominant forms of glycans attached to CMP were found to be the acidic tetrasaccharide

Received July 29, 2014.

Accepted October 17, 2014

${ }^{1}$ These authors contributed equally.

${ }^{2}$ Corresponding author: LotteBach.Larsen@agrsci.dk
$\{N$-acetyl-neuraminic acid $\quad \alpha(2-3)$ galactose $\quad \beta(1-3)$ $[N$-acetyl-neuraminic acid $\alpha(2-6)] N$-acetyl galactose $\}$ or trisaccharides $\{N$-acetyl-neuraminic acid $\alpha(2-3)$ galactose $\beta(1-3) N$-acetyl galactose and galactose $\beta(1-3)$ $[N$-acetyl-neuraminic acid $(\alpha 2-6)] N$-acetyl galactose $\}$. The CMP release was calculated to follow first-order kinetics and was determined by the measurement of CMP content during renneting. The highest rate of release for all CMP isoforms occurred from 0 to $2 \mathrm{~min}$ after chymosin addition. Concurring results from both breeds showed that CMP variant A with 1-2 P had the highest reaction rate of $\mathrm{CMP}$ release, followed by CMP B 1-2 P and then by CMP E 1-2 P (only in DH). All the identified glycosylated CMP isoforms had lower reaction rates of release compared with that of nonglycosylated CMP, thus glycan modifications seemed to negatively influence the reaction rate of chymosininduced hydrolysis of $\kappa-\mathrm{CN}$.

Key words: caseino-glycomacropeptide, milk coagulation, mass spectrometry

\section{INTRODUCTION}

Chymosin-induced coagulation of milk is the foundation of cheese making and affects both cheese yield and quality; thus, understanding this process is of importance for the dairy industry. Considerable variation has been described in cheese-making properties between batches of bulk bovine milk and, moreover, between milk samples from individual cows, both in relation to the first and second stage of chymosin-induced milk coagulation (Frederiksen et al., 2011; Poulsen et al., 2013). In the first stage, the $\mathrm{Phe}^{105}$-Met ${ }^{106}$ bond of $\kappa-\mathrm{CN}$ is cleaved by chymosin (EC 3.4.23.4) resulting in 2 peptides, that is, the hydrophobic para-k-CN ( $\kappa-\mathrm{CN}$ residues 1-105) being included in the curd and the hydrophilic caseino-macropeptide (CMP; $\kappa-\mathrm{CN}$ residues 106-169) being released into the whey. Subsequent to this process, an aggregation of the CN micelles occurs that eventually results in the formation of a gel-like 
network, called curd or coagulum, which provides a foundation for further processing into various cheeses.

One of the important factors affecting chymosininduced milk coagulation is the presence of various genetic variants of the major milk proteins (Poulsen et al., 2013). Furthermore, it has been hypothesized (Tyrisevä et al., 2008) and later confirmed that variation in protein posttranslational modification (PTM), both in relation to phosphorylation and glycosylation, can influence the coagulation properties of milk (Frederiksen et al., 2011; Jensen et al., 2012b).

At least 13 genetic variants of $\kappa$-CN-carrying amino acid substitutions have been identified in the Bos genus so far, designated A, A $A^{1}, B, C, D, E, F^{1}, F^{2}, G^{1}, G^{2}, H$, $\mathrm{I}$, and J, as reviewed by Caroli et al. (2009), with the $\mathrm{A}$ and $\mathrm{B}$ variants dominating the dairy breeds in Denmark, Danish Jersey (DJ) and Danish Holstein-Friesian (DH; Poulsen et al., 2013). Additional variation with the low-frequency $\mathrm{E}$ variant of $\kappa-\mathrm{CN}$ has been found in DH cows (Poulsen et al., 2013). Compared with the reference $\kappa-\mathrm{CN}$ variant $\mathrm{A}$, the $\mathrm{B}$ variant contains 2 substitutions $\left(\mathrm{Thr}^{157} \rightarrow\right.$ Ile, Asp ${ }^{169} \rightarrow$ Ala), whereas the $\mathrm{E}$ variant differs in 1 amino acid (Ser ${ }^{176} \rightarrow$ Gly; Caroli et al. 2009). Also, PTM variation of $\kappa-\mathrm{CN}$ contributes to further heterogeneous complexity, including phosphorylation (from 1 to $3 \mathrm{P}$ attached at sites: $\mathrm{Ser}^{148}$, $\mathrm{Thr}^{166}$ and $\mathrm{Ser}^{170}$ ) and O-glycosylation [from 1 to $6 \mathbf{G}$ attached: $\mathrm{Thr}^{142}$, $\mathrm{Thr}^{152}$, $\mathrm{Thr}^{154}, \mathrm{Thr}^{157}$ (only variant A and E), Thr ${ }^{163}$, Thr ${ }^{166}$, Thr ${ }^{186}$; Saito and Itoh, 1992; Holland et al., 2006]. Up to $60 \%$ of $\kappa$ - $\mathrm{CN}$ has been estimated to be glycosylated (Vreeman et al., 1986), where the glycoside fraction is composed of $\mathrm{N}$-acetylgalactosamine (GalNAc), galactose $(\mathbf{G a l})$, and $N$ acetyl-neuraminic acid (NeuAc; Saito and Itoh, 1992). Most glycans on the protein are present in the form of tetrasaccharides $\{56 \%$; in the form of $\operatorname{NeuAc} \alpha(2-3)$ Galß(1-3)[NeuAco (2-6)]GalNAc $\}$, but also monosaccharides $(0.8 \%$; GalNAc), disaccharides $[6.3 \%$; Gal $\beta(1-$ 3)GalNAc], and 2 trisaccharides with either a straight or a branched chain $\{18.4 \%$; NeuAco $(2-3) \operatorname{Gal} \beta(1-3)$ GalNAc and Gal $\beta(1-3)[$ NeuAc $\alpha(2-6)]$ GalNAc $\}$ are present (Saito and Itoh, 1992). In the present study, the macropeptide will, for simplicity, be noted as CMP, although it is sometimes referred to as casein glycomacropeptide (GMP) when it is glycosylated.

As the CMP moiety of $\kappa$-CN contains all sites for both genetic variation and modifications, the macropeptide can be present in several forms, denoted as isoforms. Depending on the methodology used, from 4 to $17 \mathrm{CMP}$ isoforms have been identified in milk from a single cow (Vreeman et al., 1986; Mollé and Léonil, 1995; Holland et al., 2004, 2006).

The kinetics of CMP release during renneting with chymosin is thought to follow first-order kinetics at physiological pH (van Hooydonk et al., 1984; López et al., 1997). It has been suggested that increasing carbohydrate content of CMP will lead to a decrease in the reaction rate of $\kappa$ - $\mathrm{CN}$ hydrolysis (van Hooydonk et al., 1984; Ferron-Baumy et al., 1992). The functional role of variation in phosphorylation and glycosylation on CMP, however, is not known. From a theoretical perspective, a higher initial level of glycosylation might stabilize the CN micelle structure (Holland, 2009). $\kappa$-Casein is located on the surface of the $\mathrm{CN}$ micelles with CMP protruding into the surrounding solution, which provides steric and electrostatic repulsion between micelles, preventing aggregation. Thus, increasing glycosylation of $\kappa$ - $\mathrm{CN}$ will increase the negative charge of CMP due to acidic NeuAc glycans, which most likely will affect the $\mathrm{CN}$ micelle stability. The presence of attached glycans on $\mathrm{\kappa}$-CN can furthermore be speculated to hinder the access of chymosin to the cleavage site of $\kappa-\mathrm{CN}$ during the first phase of milk coagulation, as suggested by several studies (Saito and Itoh, 1992; Brulé et al. 2000).

Variations in glycosylation degree of $\kappa-\mathrm{CN}$ and of $\kappa$-CN isoforms have been addressed in several studies (Dalgleish, 1986; Robitaille et al., 1991; Coolbear et al., 1996; Jensen et al., 2012a). In a recent larger study, no significant difference was observed between genetic variants, although $\kappa-\mathrm{CN} \mathrm{BB}$ was found to have a slightly higher glycosylation degree compared with $\kappa-\mathrm{CN} \mathrm{AB}$ and AA (Bonfatti et al., 2014). Using twodimensional gels combined with mass spectrometry, we have previously investigated the PTM pattern of $\kappa$-CN variant E (Jensen et al., 2012a). However, reports of the glycosylation pattern of $\kappa_{-} \mathrm{CN}$ variant $\mathrm{E}$ are very limited and thus invite further investigation. Furthermore, correlation between the glycosylation degree of $\kappa-\mathrm{CN}$ and $\mathrm{CN}$ micelle size has been established, with smaller micelles being associated with a higher glycosylation degree (Bijl et al., 2014). Smaller micelles also confer improved chymosin-induced coagulation properties observed with shorter coagulation time and firmer gel strength (Glantz et al., 2010; Frederiksen et al., 2011). Likewise, a consensus persists concerning a positive correlation between the $\kappa-\mathrm{CN}$ variant $\mathrm{B}$ and a high relative concentration of $\kappa-\mathrm{CN}$ in milk (Bonfatti et al., 2014), improved coagulation, and improved cheese yields (Ikonen et al., 1999; Wedholm et al., 2006). Opposite to this, the $\kappa-\mathrm{CN} \mathrm{A}$ and $\mathrm{E}$ variants have been correlated with poor milk-clotting properties (e.g., longer coagulation time and lower gel strength; Ikonen et al., 1999; Wedholm et al., 2006; Poulsen et al., 2013).

Previous studies documenting the kinetics of CMP release during chymosin-induced milk coagulation and renneting have used pooled bulk milk samples that contain a mixture of all genetic variants of $k-\mathrm{CN}$ (van 
Hooydonk et al., 1984; Ferron-Baumy et al., 1992). Therefore, the objectives of the present study were to identify distinct CMP isoforms in relation to genetic and PTM variation and to estimate the release of CMP in milk from DJ and DH cows. The milk samples from individual cows were selected to represent distinct homo- and heterozygous genotypes of the $\mathrm{k}$ - $\mathrm{CN}$ genetic variants $\mathrm{A}, \mathrm{B}$, and $\mathrm{E}$. To our knowledge, this is the first study on the reaction rate for CMP release in relation to genetic variation and a novelty is the analysis of $\kappa-\mathrm{CN}$ variant $\mathrm{E}$ both in regard to protein PTM and kinetic rate of CMP release during renneting.

\section{MATERIALS AND METHODS}

\section{Milk Samples}

Milk samples were collected from individual DJ and DH cows as outlined in Poulsen et al. (2013). A milk subset was selected based on $\kappa$-CN genotype which previously had been determined (Jensen et al., 2012a), including 12 milk samples from DJ cows (representing 4 samples with $\kappa$-CN genotype $\mathrm{AA}, 4 \kappa-\mathrm{CN} \mathrm{AB}$, and 4 $\kappa-\mathrm{CN} \mathrm{BB}$ ) and 17 samples from DH cows (representing 4 samples with $\kappa-\mathrm{CN}$ AA, 2 k-CN BB, 5 k-CN AB, $2 \kappa-\mathrm{CN} \mathrm{EE}$, and $4 \kappa-\mathrm{CN} \mathrm{AE})$. The selection of $\mathrm{DH}$ cow samples was due to the presence of the additional genetic variant $\mathrm{E}$ of $\kappa-\mathrm{CN}$ and low frequencies of homozygote BB and EE in this breed (Poulsen et al., 2013). Also, 2 pooled samples from each breed were generated by mixing equal amounts of the individual samples. The samples were skimmed at 2,643 $\times g$ for $30 \mathrm{~min}$ at $4^{\circ} \mathrm{C}$ and kept at $-20^{\circ} \mathrm{C}$ until further analysis.

\section{Sample Pretreatment}

Milk samples were thawed at $5^{\circ} \mathrm{C}$ before equilibrating in a water bath at $30^{\circ} \mathrm{C}$ for 30 min. Milk pH was adjusted to 6.5 with $10 \% \mathrm{vol} / \mathrm{vol}$ lactic acid. Each sample was analyzed in triplicate for both protein profiling and CMP analysis.

Protein Profiling. Each sample was analyzed without addition of chymosin and after $40 \mathrm{~min}$ of renneting. For renneting, chymosin [Chy-Max Extra, 615 international milk clotting units (IMCU) per $\mathrm{mL}$, Chr. Hansen, Hørsholm, Denmark] was added to a final concentration of $0.035 \mathrm{IMCU} / \mathrm{mL}$. To stop the chymosin-induced hydrolysis after $40 \mathrm{~min}, 1 \mathrm{~mL}$ of reduction buffer consisting of $6 M$ urea and $100 \mathrm{mM}$ trisodium citrate-dihydrate was added to $200-\mu \mathrm{L}$ milk samples, followed by the addition of $20 \mu \mathrm{L} 15 \mathrm{mM}$ dithiothreitol in sodium acetate trihydrate ( $\mathrm{pH} 5.2)$ and vortexing until the precipitate was dispersed. Samples were then placed in a rotation oven at $30^{\circ} \mathrm{C}$ for $60 \mathrm{~min}$ and centrifuged at $9,300 \times g$ at $4^{\circ} \mathrm{C}$ for $10 \mathrm{~min}$, and the supernatant was collected for liquid chromatographymass spectrometry (LC-MS) analysis.

CMP Analysis. Chymosin (Chy-Max Extra, 615 IMCU per $\mathrm{mL}$, Chr. Hansen) was added to each sample to a final concentration of $0.035 \mathrm{IMCU} / \mathrm{mL}$ followed by mixing. Samples of $1 \mathrm{~mL}$ were immediately aliquoted into Eppendorf tubes (Sigma-Aldrich, St. Louis, MO) to be analyzed at timed intervals of $0,2,4,6,8,10,13$, 16, 19, 22, 30, and $40 \mathrm{~min}$. Samples were incubated at $30^{\circ} \mathrm{C}$. To stop the chymosin-induced hydrolysis and to precipitate the whey proteins, TCA was added to the samples to a final concentration of $1 \% \mathrm{wt} / \mathrm{vol}$ TCA. This was followed by mixing and centrifugation at $4^{\circ} \mathrm{C}$ at $9,300 \times g$ for $10 \mathrm{~min}$, and the supernatant was collected for LC-MS analysis.

\section{LC-MS Analysis of Protein and CMP}

Proteomic profiling was performed using a reversedphase ultra HPLC equipment consisting of an Agilent 1290 system (Agilent Technologies, Santa Clara, CA) operated with a mixture of solvent A consisting of $0.05 \% \mathrm{vol} / \mathrm{vol}$ trifluoroacetic acid and solvent B of $0.1 \%$ $\mathrm{vol} / \mathrm{vol}$ trifluoroacetic acid in $99.9 \% \mathrm{vol} / \mathrm{vol}$ acetonitrile. For protein analysis, $5 \mu \mathrm{L}$ of milk sample was injected onto a Biosuite C18 PA-B column $(250 \times 2.1$ $\mathrm{mm}, 3.5 \mu \mathrm{m}$ pore size, $300 \AA$, Waters, Milford, MA) operated at $45^{\circ} \mathrm{C}$ using a linear gradient from 33.3 to $45.6 \%$ solvent B in 14.7 min with a flow rate of 0.35 $\mathrm{mL} / \mathrm{min}$. For CMP analysis, $20 \mu \mathrm{L}$ of sample was injected into a Symmery 300 C18 column $(150 \times 2.1 \mathrm{~mm}$, $5 \mu \mathrm{m}$ pore size, $300 \AA$, Waters) operated at $60^{\circ} \mathrm{C}$ using a linear gradient from 18 to $48 \%$ solvent $\mathrm{B}$ in $15 \mathrm{~min}$ with a flow rate of $0.5 \mathrm{~mL} / \mathrm{min}$. The compounds were detected in the effluent by measuring UV absorbance at $214 \mathrm{~nm}$, which was coupled with a high-resolution mass spectrometer, quadrupole time of flight, with an electrospray ionization jet stream interface $(6530 \mathrm{Ac}-$ curate, Q-TOF-LC/MS, Agilent). The LC-MS setting included: positive ion polarity, mass range $=500$ to $2,500 \mathrm{~m} / \mathrm{z}$, and scan rate $=0.7 / \mathrm{s}$. Agilent MassHunter Software (version B.03.01) with the add-on software Bioconfirm was used for the qualitative and quantitative analysis to create UV and total ion current chromatograms, as well as extracted ion chromatograms (EIC). The weighted average of the isotopic masses (average mass, $\mathbf{M}_{\mathbf{w}}$ ) of the compounds was calculated from the total ion current using the deconvolution algorithm included in the Bioconfirm software. The average mass was used for compound identification searching either an in-house milk protein database developed by Arla Strategic Innovation Centre (Arla Foods amba) or a newly created CMP database. 
Relative protein content was calculated based on integration of peak area in the UV chromatograms, and the F-test was performed to evaluate differences in the relative $\mathrm{k}-\mathrm{CN}$ content and the fraction of glycosylated $\kappa-C N$. Also, the relative content of CMP was quantified from EIC, where CMP isoforms were identified and integrated with at least 3 extracted ions (i.e., 1 quantifier and at least 1 qualifier ion).

\section{CMP Database}

A database was constructed using the database generator from the General Protein/Mass Analysis software for Windows (GPMAW, Light House Data, Odense, Denmark) to identify glycosylated and phosphorylated forms of CMP variants (A, B, and E). References masses of the nonglycosylated CMP variants included CMP A-1P $\left(\mathrm{M}_{\mathrm{w}}=6,787.62 \mathrm{Da}\right)$, CMP B-1P $\left(\mathrm{M}_{\mathrm{w}}=6,755.63 \mathrm{Da}\right)$, and CMP E-1P $\left(\mathrm{M}_{\mathrm{w}}=6,757.63\right.$ $\mathrm{Da})$. The database included single to triple phosphorylations (1-3 P) and single to triple glycosylations (1-3 G) with the 5 predominating glycosylated forms, which for simplicity have been denoted with lowercase letters: $\mathbf{a}=$ GalNAc $\left(\mathrm{M}_{\mathrm{w}}=221.2 \mathrm{Da}\right), \mathbf{b}=\operatorname{Gal} \beta(1-3)$ GalNAc $\left(\mathrm{M}_{\mathrm{w}}=383.3 \mathrm{Da}\right), \mathbf{c}=\operatorname{NeuAc\alpha }(2-3) \mathrm{Gal} \beta(1-3)$ GalNAc $\left(\mathrm{M}_{\mathrm{w}}=674.6 \mathrm{Da}\right), \mathbf{d}=\operatorname{Gal} \beta(1-3)[\mathrm{NeuAc} \alpha(2-6)] \mathrm{Gal}-$ $\mathrm{NAc}\left(\mathrm{M}_{\mathrm{w}}=674.6 \mathrm{Da}\right)$, and $\mathbf{e}=\operatorname{NeuAc\alpha }(2-3) \mathrm{Gal} \beta(1-3)$ $[$ NeuAco $(2-6)]$ GalNAc $\left(\mathrm{M}_{\mathrm{w}}=965.6 \mathrm{Da}\right)$. Table 1 provides an overview of the masses of the potential PTM included in the database, representing the predominant modifications previously identified on bovine $\kappa-\mathrm{CN}$ (Holland et al., 2006; Holland, 2009), as well as associated sodium adducts.

\section{Calculation of Reaction Rate of CMP Release}

By using the solver function in Microsoft Excel 2010 (Microsoft Corp., Redmond, WA), nonlinear fit for each identified CMP isoform was created to make plots of CMP release in relation to time. The solver function was used to fit a curve to the measurements by estimating the reaction rate of CMP release by decreasing the sum of the squared deviation between the calculated CMP and the determined CMP at different times. The reaction rate constant of CMP release, $k$, was used as measurement of the rate of CMP release during renneting, and $k$ was calculated based on the equation

$$
\operatorname{CMP}(t)=\mathrm{CMP}_{\max } \times\left(1-\mathrm{e}^{-k \times t}\right),
$$

where $\mathrm{CMP}(t)$ equals the amount of $\mathrm{CMP}$ released at time $t$, and $\mathrm{CMP}_{\max }$ equals the maximum amount of CMP released.

\section{RESULTS}

\section{Protein Profiling Before and After Hydrolysis by Chymosin}

The protein profile of pooled and individual DJ and $\mathrm{DH}$ milk samples, representing distinct $\kappa-\mathrm{CN}$ genotypes (i.e., genotypes $\mathrm{AA}, \mathrm{BB}, \mathrm{AB}, \mathrm{EE}$, and $\mathrm{AE}$ ), was determined before and after chymosin addition using LC-MS

Table 1. Masses of potential posttranslational modifications on caseino-macropeptide (CMP) isoforms

\begin{tabular}{|c|c|}
\hline $\begin{array}{l}\text { Posttranslational } \\
\text { modification }^{1}\end{array}$ & $\begin{array}{l}\mathrm{M}_{\mathrm{w}} \\
(\mathrm{Da})\end{array}$ \\
\hline Nonmodified & -79.98 \\
\hline $1 \mathrm{P}$ (reference) & 0 \\
\hline $2 \mathrm{P}$ & 79.98 \\
\hline $3 \mathrm{P}$ & 157.96 \\
\hline $1 \mathrm{P} 1 \mathrm{G}(\mathrm{a})$ & 203.19 \\
\hline $2 \mathrm{P} 1 \mathrm{G}(\mathrm{a})$ & 283.17 \\
\hline $1 \mathrm{P} 1 \mathrm{G}(\mathrm{b})$ & 365.34 \\
\hline $1 \mathrm{P} 2 \mathrm{G}(\mathrm{a}, \mathrm{a})$ & 406.39 \\
\hline $2 \mathrm{P} 1 \mathrm{G}(\mathrm{b})$ & 445.32 \\
\hline $1 \mathrm{P} 2 \mathrm{G}(\mathrm{a}, \mathrm{b})$ & 568.53 \\
\hline $1 \mathrm{P} 3 \mathrm{G}(\mathrm{a}, \mathrm{a}, \mathrm{a})$ & 609.58 \\
\hline $1 \mathrm{P} 1 \mathrm{G}(\mathrm{c} / \mathrm{d})$ & 656.59 \\
\hline $1 \mathrm{P} 2 \mathrm{G}(\mathrm{b}, \mathrm{b})$ & 730.67 \\
\hline $2 \mathrm{P} 1 \mathrm{G}(\mathrm{c} / \mathrm{d})$ & 736.57 \\
\hline $1 \mathrm{P} 3 \mathrm{G}(\mathrm{a}, \mathrm{a}, \mathrm{b})$ & 771.72 \\
\hline $1 \mathrm{P} 2 \mathrm{G}(\mathrm{a}, \mathrm{c} / \mathrm{d})$ & 859.79 \\
\hline $1 \mathrm{P} 3 \mathrm{G}(\mathrm{b}, \mathrm{b}, \mathrm{a})$ & 933.87 \\
\hline $1 \mathrm{P} 1 \mathrm{G}(\mathrm{e})$ & 947.85 \\
\hline $1 \mathrm{P} 2 \mathrm{G}(\mathrm{b}, \mathrm{c} / \mathrm{d})$ & $1,021.93$ \\
\hline $2 \mathrm{P} 1 \mathrm{G}(\mathrm{e})$ & $1,027.83$ \\
\hline $1 \mathrm{P} 3 \mathrm{G}(\mathrm{a}, \mathrm{a}, \mathrm{c} / \mathrm{d})$ & $1,062.98$ \\
\hline $1 \mathrm{P} 3 \mathrm{G}(\mathrm{b}, \mathrm{b}, \mathrm{b})$ & $1,096.01$ \\
\hline $1 \mathrm{P} 2 \mathrm{G}(\mathrm{a}, \mathrm{e})$ & $1,151.05$ \\
\hline $1 \mathrm{P} 3 \mathrm{G}(\mathrm{a}, \mathrm{b}, \mathrm{c} / \mathrm{d})$ & $1,225.13$ \\
\hline $1 \mathrm{P} 2 \mathrm{G}(\mathrm{b}, \mathrm{e})$ & $1,313.19$ \\
\hline $1 \mathrm{P} 2 \mathrm{G}(\mathrm{c} / \mathrm{d}, \mathrm{c} / \mathrm{d})$ & $1,313.19$ \\
\hline $1 \mathrm{P} 3 \mathrm{G}(\mathrm{a}, \mathrm{a}, \mathrm{e})$ & $1,354.24$ \\
\hline $1 \mathrm{P} 3 \mathrm{G}(\mathrm{b}, \mathrm{b}, \mathrm{c} / \mathrm{d})$ & $1,387.27$ \\
\hline $1 \mathrm{P} 3 \mathrm{G}(\mathrm{a}, \mathrm{b}, \mathrm{e})$ & $1,516.38$ \\
\hline $1 \mathrm{P} 3 \mathrm{G}(\mathrm{c} / \mathrm{d}, \mathrm{c} / \mathrm{d}, \mathrm{a})$ & $1,516.38$ \\
\hline $1 \mathrm{P} 2 \mathrm{G}(\mathrm{c} / \mathrm{d}, \mathrm{e})$ & $1,604.45$ \\
\hline $1 \mathrm{P} 3 \mathrm{G}(\mathrm{b}, \mathrm{b}, \mathrm{e})$ & $1,678.53$ \\
\hline $1 \mathrm{P} 3 \mathrm{G}(\mathrm{c} / \mathrm{d}, \mathrm{c} / \mathrm{d}, \mathrm{b})$ & $1,678.53$ \\
\hline $1 \mathrm{P} 3 \mathrm{G}(\mathrm{a}, \mathrm{c} / \mathrm{d}, \mathrm{e})$ & $1,807.64$ \\
\hline $1 \mathrm{P} 2 \mathrm{G}(\mathrm{e}, \mathrm{e})$ & $1,895.71$ \\
\hline $1 \mathrm{P} 3 \mathrm{G}(\mathrm{b}, \mathrm{c} / \mathrm{d}, \mathrm{e})$ & $1,969.78$ \\
\hline $1 \mathrm{P} 3 \mathrm{G}(\mathrm{c} / \mathrm{d}, \mathrm{c} / \mathrm{d}, \mathrm{c} / \mathrm{d})$ & $1,969.78$ \\
\hline $1 \mathrm{P} 3 \mathrm{G}(\mathrm{a}, \mathrm{e}, \mathrm{e})$ & $2,098.90$ \\
\hline $1 \mathrm{P} 3 \mathrm{G}(\mathrm{c} / \mathrm{d}, \mathrm{c} / \mathrm{d}, \mathrm{e})$ & $2,261.04$ \\
\hline $1 \mathrm{P} 3 \mathrm{G}(\mathrm{b}, \mathrm{e}, \mathrm{e})$ & $2,261.04$ \\
\hline $1 \mathrm{P} 3 \mathrm{G}(\mathrm{c} / \mathrm{d}, \mathrm{e}, \mathrm{e})$ & $2,552.30$ \\
\hline $1 \mathrm{P} 3 \mathrm{G}(\mathrm{e}, \mathrm{e}, \mathrm{e})$ & $2,843.56$ \\
\hline
\end{tabular}

${ }^{1}$ Modifications include single to triple phosphorylations $(1-3 \mathrm{P})$ and single to triple glycosylations $(1-3 \mathrm{G})$. Lowercase letters in parentheses refer to the 5 predominating glycosylation forms; a $=N$-acetylgalactosamine (GalNAc), b = galactose (Gal) $\beta(1-3)$ GalNAc, c $=N$-acetyl-neuraminic acid (NeuAc) $\alpha(2-3)$ Gal $\beta 1-3 G a l N A c, d=$ $\operatorname{Gal} \beta(1-3)[\operatorname{NeuAc} \alpha(2-6)]$ GalNAc, and $\mathrm{e}=\operatorname{NeuAc} \alpha(2-3) \operatorname{Gal} \beta(1-3)$ $[$ NeuAco $(2-6)]$ GalNAc. The glyco-forms $c$ and $d$ have the same mass and could not be discriminated from each other, thus $\mathrm{c} / \mathrm{d}$ refers to either of these forms. 
analysis. Figure 1 shows an overlay of UV chromatograms analyzing protein profiles of pooled milk samples at $0 \mathrm{~min}$ (denoted as no renneting) and after $40 \mathrm{~min}$ of renneting with chymosin applying DJ milk and DH milk. Protein profiles before and after addition of chymosin were relatively similar, with the exception of the $\mathrm{k}$-CN elution area. Without the hydrolyzing action of chymosin, $\kappa-\mathrm{CN}$ eluted in 3 major peaks: the first peak (3.4 min; Figure 1) contained various glycosylated forms of $\kappa-\mathrm{CN}\left(\mathrm{M}_{\mathrm{w}}>19,000 \mathrm{Da}\right)$; the second peak (4.8 min; Figure 1a, b) contained 2 nonglycosylated $\kappa-\mathrm{CN}$ variants, $\kappa-\mathrm{CN}$ A $1 \mathrm{P}\left(\mathrm{M}_{\mathrm{w}}=19,038 \mathrm{Da}\right)$ and $\kappa-\mathrm{CN} \mathrm{E}$ $1 \mathrm{P}\left(\mathrm{M}_{\mathrm{w}}=19,008 \mathrm{Da}\right)$, eluting at similar times due to similar physico-chemical protein properties; and the last peak (7.1 min; Figure 1) contained nonglycosylated $\kappa-\mathrm{CN}$ B $1 \mathrm{P}\left(\mathrm{M}_{\mathrm{w}}=19,006 \mathrm{Da}\right)$. After $40 \mathrm{~min}$ of renneting, however, these 3 peaks identified as intact k-CN forms were replaced with 1 large peak (4.6 min; Figure 1) that was identified as being para- $\kappa-\mathrm{CN}\left(\mathrm{M}_{\mathrm{w}}=\right.$ $12,268 \mathrm{Da})$, thus validating that the majority of intact $\kappa$-CN was hydrolyzed by chymosin.

Chromatographic integration of the $\kappa-\mathrm{CN}$ elution area $(2.8-7.5 \mathrm{~min})$ in the protein profile for the individual samples gave the quantitative estimate that $>90 \%$ of intact $\kappa-\mathrm{CN}$ in both breeds was hydrolyzed after 40 min of renneting. Following the elution interval of $\kappa-\mathrm{CN}$, all the other major milk proteins eluted in the order of $\alpha_{\mathrm{S} 2}-\mathrm{CN}$ variant A $10-12 \mathrm{P}\left(\mathrm{M}_{\mathrm{w}}=25,157-25,319\right.$ $\mathrm{Da}), \alpha_{\mathrm{S} 1} \mathrm{CN}$ variant B 8-9P $\left(\mathrm{M}_{\mathrm{w}}=23,623-23,704 \mathrm{Da}\right)$, $\beta$-CN variant $\mathrm{B} 5 \mathrm{P}\left(\mathrm{M}_{\mathrm{w}}=24,097 \mathrm{Da}\right), \beta-\mathrm{CN}$ variant A1 $5 \mathrm{P}\left(\mathrm{M}_{\mathrm{w}}=24,028 \mathrm{Da}\right), \beta-\mathrm{CN}$ variant $\mathrm{A} 25 \mathrm{P}\left(\mathrm{M}_{\mathrm{w}}=\right.$ $23,988 \mathrm{Da}), \alpha-\mathrm{LA}\left(\mathrm{M}_{\mathrm{w}}=14,177 \mathrm{Da}\right), \beta-\mathrm{LG}$ variant $\mathrm{B}$ $\left(\mathrm{M}_{\mathrm{w}}=18,276 \mathrm{Da}\right)$, and $\beta-\mathrm{LG}$ variant $\mathrm{A}\left(\mathrm{M}_{\mathrm{w}}=18,361\right.$ Da). Also, plasmin degradation productions of $\beta-\mathrm{CN}$ were identified: $\beta$-CN residues $106-209\left(\mathrm{M}_{\mathrm{w}}=11,823\right.$ Da) and $\beta-C N$ residues $108-209\left(\mathrm{M}_{\mathrm{w}}=11,558 \mathrm{Da}\right)$.

\section{Relative Quantification of $\mathrm{K}-\mathrm{CN}$ and Glycosylated $\mathrm{K}-\mathrm{CN}$}

Table 2 shows the relative content of $\kappa-\mathrm{CN}$ and the fraction of glycosylated $\kappa-\mathrm{CN}$ in relation to breed and $\kappa-C N$ genotype. Chromatographic integration of the k-CN elution area (2.8-7.5 min; Figure 1) in relation to total elution area $(2.8-19 \mathrm{~min})$ in individual milk samples estimated that a significantly higher $\kappa-\mathrm{CN}$ content relative to total protein was found for BB milk, and lowest for $\mathrm{AE}$ milk. Likewise, the relative fraction of glycosylated $\kappa$-CN was calculated by comparing the integrated area of the first peak identified as glycosylated $\kappa-\mathrm{CN}(2.8-4 \mathrm{~min})$ to the $\kappa-\mathrm{CN}$ elution area (2.8-7.5 min). No significant difference in the level of glycosylated $\kappa$-CN to total $\mathrm{CN}$ was observed between the genetic variants, although the highest level was detected in $\mathrm{BB}$ milk in $\mathrm{DH}$.

\section{CMP Isoform Identification}

Figure 2 shows the chromatographic overlay of the CMP isoform released at different time points in DJ and DH pooled samples after addition of chymosin. Two major peaks (8.2 and 9.5 min; Figure 2) were identified; the first peak contained CMP A $1 P$ and CMP E $1 P$ (only in $\mathrm{DH}$ ), whereas the second peak contained CMP B 1P. Furthermore, CMP A $2 \mathrm{P}$ and E $2 \mathrm{P}$ and CMP B $2 \mathrm{P}$ were also identified in these 2 peaks. Great variety was identified in CMP glycosylation; the predominant CMP glycosylation form in both breeds was found to be the e form, followed by $\mathrm{c} / \mathrm{d}$, whereas a and b were only rarely identified in the samples. The majority of the glycosylated CMP isoforms eluted first (retention times of 5.6-8 min), with the most glycosylated isoforms comprising a higher number of attached glycans resulting in lower retention times. In addition, nonmodified CMP (only identified in individual samples) eluted later than the modified forms of CMP in 2 separate peaks, with the first peak (9.1 min) containing CMP A or CMP E and the second peak (10.4 min) containing CMP B. Also, some CMP isoforms were identified representing different sites of O-linked attachments, as denoted by a number in connection with the CMP isoform name [e.g., CMP A 2P was identified in 2 separated peaks with retention time 7.7 min (denoted as CMP A 2P 2; Figure 2a) and with retention time of $8.2 \mathrm{~min}$ (denoted as CMP A 2P 1; Figure 2a)]. Finally, sodium adducts on the CMP isoforms were identified with mass additions of $21.99 \mathrm{Da}$, which might originate naturally from the milk or may have been introduced during sample preparation.

\section{CMP Isoform Distribution}

The number of CMP isoforms identified varied to some extent between breeds and between $\mathrm{\kappa}-\mathrm{CN}$ genetic variants; $21 \mathrm{CMP}$ isoforms were identified in DJ milk (12 derived from $\kappa$-CN A and 9 from $\kappa$-CN B allele) and $26 \mathrm{CMP}$ isoforms were identified in $\mathrm{DH}$ milk (15 derived from $\kappa-\mathrm{CN} \mathrm{A,} 5$ from $\kappa-\mathrm{CN} \mathrm{B}$, and 6 from $\kappa-\mathrm{CN}$ $\mathrm{E})$. The number of CMP isoforms also varied within individual samples of each breed, with 7 to $18 \mathrm{CMP}$ isoforms for DJ cows and 3 to 15 CMP isoform for DH cows. The majority of these CMP isoforms were also identified in the pooled milk samples, although a few were only identified in the milk samples from individual cows, most likely due to a dilution effect in the pooled samples. 

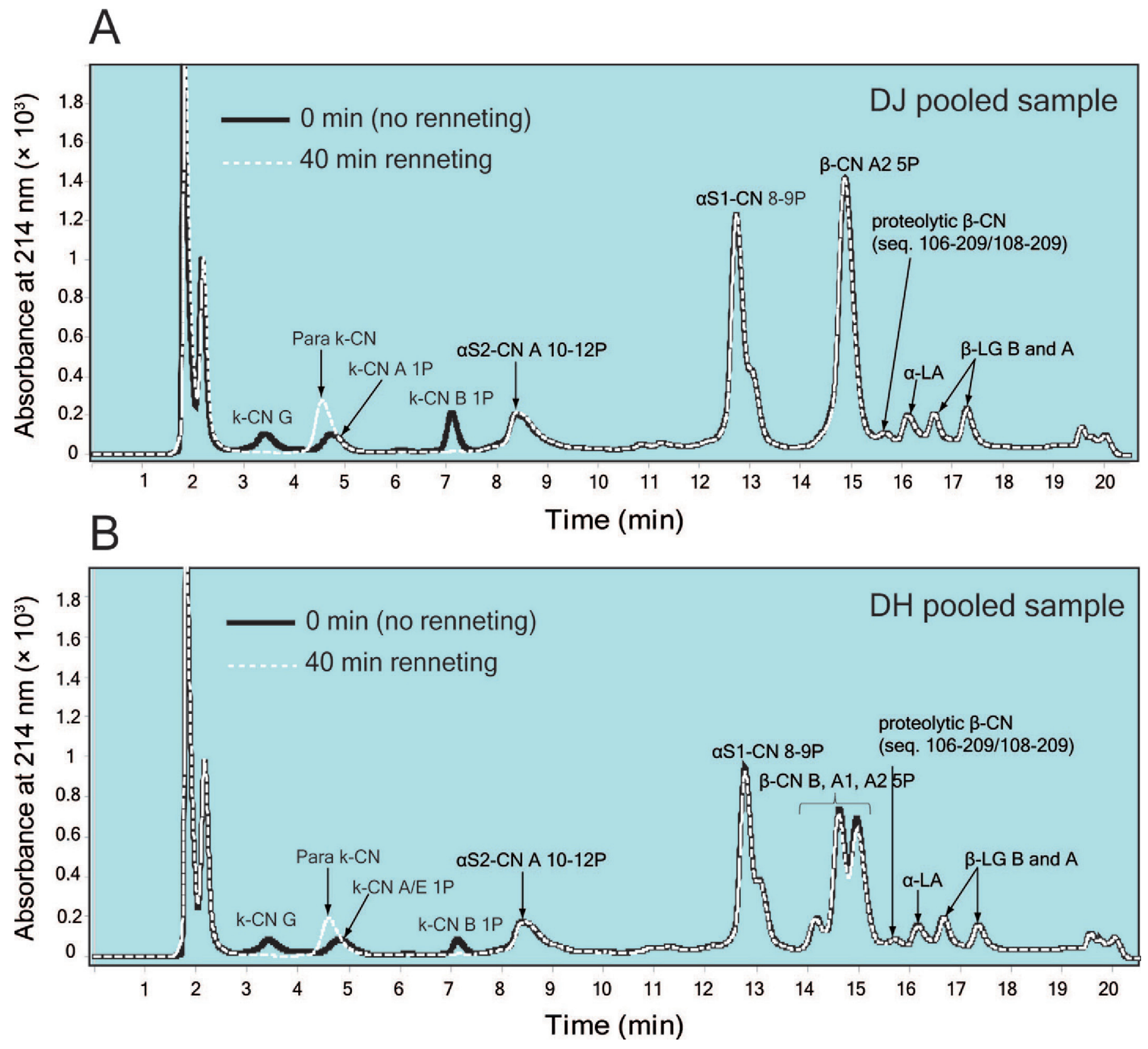

Figure 1. Overlay of UV chromatograms analyzing protein profiles before and after addition of chymosin to pooled milk samples from (A) Danish Jersey (DJ) and (B) Danish Holstein-Friesian (DH). The samples were assessed at time point 0 min (denoted as no renneting) and after 40 min of renneting. All major milk proteins (with noted genetic variation and modifications) were identified, as well as proteolytic $\beta$-CN products. Color version available online.

\section{Release of CMP Isoforms During Chymosin-Induced Hydrolysis of $\mathrm{K}-\mathrm{CN}$}

The kinetics of CMP release was followed as a measurement of CMP content using EIC calculation during LC-MS analysis during 40 min of renneting in both pooled samples and samples from individual DJ and DH cows. Figure 3 shows CMP release during renneting in DH pooled milk where the release of CMP A
1P, CMP B 1P, and CMP E 1P are exemplified. Direct nonlinear fits of the CMP release of the distinct CMP isoforms were made and followed during the 40-min period of incubation with chymosin, denoted $\mathrm{P}(\mathrm{t})$. The largest increase in CMP release occurred from 0 to 2 min of chymosin-hydrolysis, followed by a more or less steady increase up to $15 \mathrm{~min}$, after which the reaction reached a plateau with no further CMP hydrolysis occurring. 
Table 2. Relative content of $\kappa-\mathrm{CN}$ and fraction of glycosylated $\kappa-\mathrm{CN}[$ mean $(\%) \pm \mathrm{SD}$ ] in relation to breed and $\kappa$-CN genotype

\begin{tabular}{|c|c|c|c|}
\hline Breed & $\begin{array}{l}\kappa-\mathrm{CN} \text { genotype } \\
\text { (no. of samples) }\end{array}$ & $\begin{array}{l}\kappa-\mathrm{CN} / \text { total } \\
\text { protein }\end{array}$ & $\begin{array}{l}\text { Glycosylated } \\
\kappa-\mathrm{CN} / \kappa-\mathrm{CN}\end{array}$ \\
\hline \multirow[t]{3}{*}{ DJ } & $\mathrm{AA}(4)$ & $8.18 \pm 0.68^{\mathrm{b}}$ & $30.21 \pm 5.26$ \\
\hline & $\mathrm{BB}(4)$ & $10.32 \pm 0.91^{\mathrm{a}}$ & $26.70 \pm 4.07$ \\
\hline & $\mathrm{AB}(4)$ & $9.42 \pm 1.33^{\mathrm{b}}$ & $28.89 \pm 4.63$ \\
\hline \multirow[t]{5}{*}{$\mathrm{DH}$} & $\mathrm{AA}(4)$ & $9.01 \pm 2.58^{\mathrm{bc}}$ & $34.98 \pm 6.68$ \\
\hline & $\mathrm{BB}(2)$ & $11.26 \pm 1.10^{\mathrm{a}}$ & $45.84 \pm 9.07$ \\
\hline & $\mathrm{AB}(5)$ & $8.10 \pm 1.33^{\mathrm{bc}}$ & $29.82 \pm 1.87$ \\
\hline & $\mathrm{EE}(2)$ & $8.09 \pm 0.71^{\mathrm{bc}}$ & $31.67 \pm 6.23$ \\
\hline & $\mathrm{AE}(4)$ & $6.92 \pm 1.36^{\mathrm{b}}$ & $31.81 \pm 6.34$ \\
\hline
\end{tabular}

${ }^{\mathrm{a}-\mathrm{c}}$ Significant variation $(P<0.05)$ was determined between the $\mathrm{k}-\mathrm{CN}$ genotypes within each breed.

Figure 4 shows the calculated rates of CMP release for each of the distinct CMP isoforms in individual DJ and DH milk samples after 2 min of renneting. The same trend emerged for both breeds; CMP A 1-2P had the highest rate of CMP release, followed by CMP B 1-2P and by CMP E 1-2P (only DH milk). Overall, all of the identified glycosylated CMP isoforms had a lower rate of CMP release than nonglycosylated CMP, with only 1 exception in DH milk [i.e., CMP B 1P 3G (b, e, e or c/d, c/d, e)] also having a high standard deviation. Thus, glycan modification seemed to negatively influence chymosin-induced hydrolysis of $\kappa-\mathrm{CN}$. Also, CMP forms having identical molecular composition, but with variation in modification sites, did not necessarily have similar reaction rates of CMP release. This could indicate that the site of modification may be of importance during hydrolysis induced by chymosin.

\section{DISCUSSION}

The present study leads to a better understanding of the variations in the susceptibility of different isoforms and genetic variants of $\kappa-\mathrm{CN}$ for cleavage by chymosin. Although this knowledge is important from a scientific point of view, the CMP heterogeneity is also important practically for the dairy industry, as it allows an understanding of why the rate of the renneting step, which is applied during cheese production, may alter. This modified rate of hydrolysis may ultimately allow the possibility of decreasing variations in cheese yield and consequently increasing cheese yield, an important economical production factor.

Analysis of the protein profile by LC-MS of individual DJ and DH milk samples showed that $>90 \%$ of intact $\kappa-\mathrm{CN}$ in both breeds was hydrolyzed after 40 min by chymosin (with a final concentration of 0.035 $\mathrm{IMCU} / \mathrm{mL}$ ), with 1 large peak identified as para-k-CN replacing 3 peaks identified as intact $\kappa-\mathrm{CN}$ forms in the chromatograms. Also, the relative content of $\kappa-\mathrm{CN}$ was found to be significantly different between $k$-CN genotypes, with $\kappa$-CN genotype $\mathrm{BB}$ having the highest relative content of $\kappa-\mathrm{CN}$ to total protein in both breeds, confirming other studies (Bonfatti et al., 2014). In the present investigation, no significant difference in the level of glycosylation in relation to $\kappa-\mathrm{CN}$ genetic variant (A, B, E) was found, although considerable heterogeneity was observed between individual cows; in $\mathrm{DH}$, the highest level was detected in BB milk, in agreement with other studies (Robitaille et al., 1991; Lieske et al., 1996; Bonfatti et al., 2014). It has been difficult to obtain consensus regarding which genetic variant of $\kappa-\mathrm{CN}$ relates to the highest level of glycosylation; Coolbear et al. (1996) and Robitaille et al. (1991) found a higher concentration of glycosylated $\kappa-\mathrm{CN}$ in milk of $\kappa-\mathrm{CN} \mathrm{BB}$ than AA, whereas no variation or contradictory results have also been reported (Dalgleish, 1986; Jensen et al., 2012a,b). Recently, a large number of samples were investigated using reverse phase-HPLC, where $\kappa-\mathrm{CN}$ $\mathrm{BB}$ was found to have a slightly higher glycosylation degree compared with $\kappa-\mathrm{CN} \mathrm{AB}$ and $\mathrm{AA}$ (Bonfatti et al., 2014). The inconsistencies across studies may be ascribed to reasons such as differences in used analytical approaches or limited sample size; furthermore, many biological factors affecting $\mathrm{k}$-CN glycosylation are not fully understood.

The LC-MS approach employed for determining the protein profile and overall protein composition was optimized for profiling major milk proteins, not for detection of CMP. Therefore, the profile of CMP was determined by a complementary LC-MS method with a supplementary sample preparation. This allowed for an in-depth identification of CMP isoforms generated during renneting, including uncovering the PTM degree of the CMP genetic variants (A, B, and E). Trichloroacetic acid fractionation (1\% wt/vol) was used to isolate CMP previously optimized by Thomä et al. (2006). The amount of CMP left in the supernatant of renneted milk was proportional to the concentration of TCA used to precipitate the other milk proteins, as well on the amount of glycosylation of the individual 

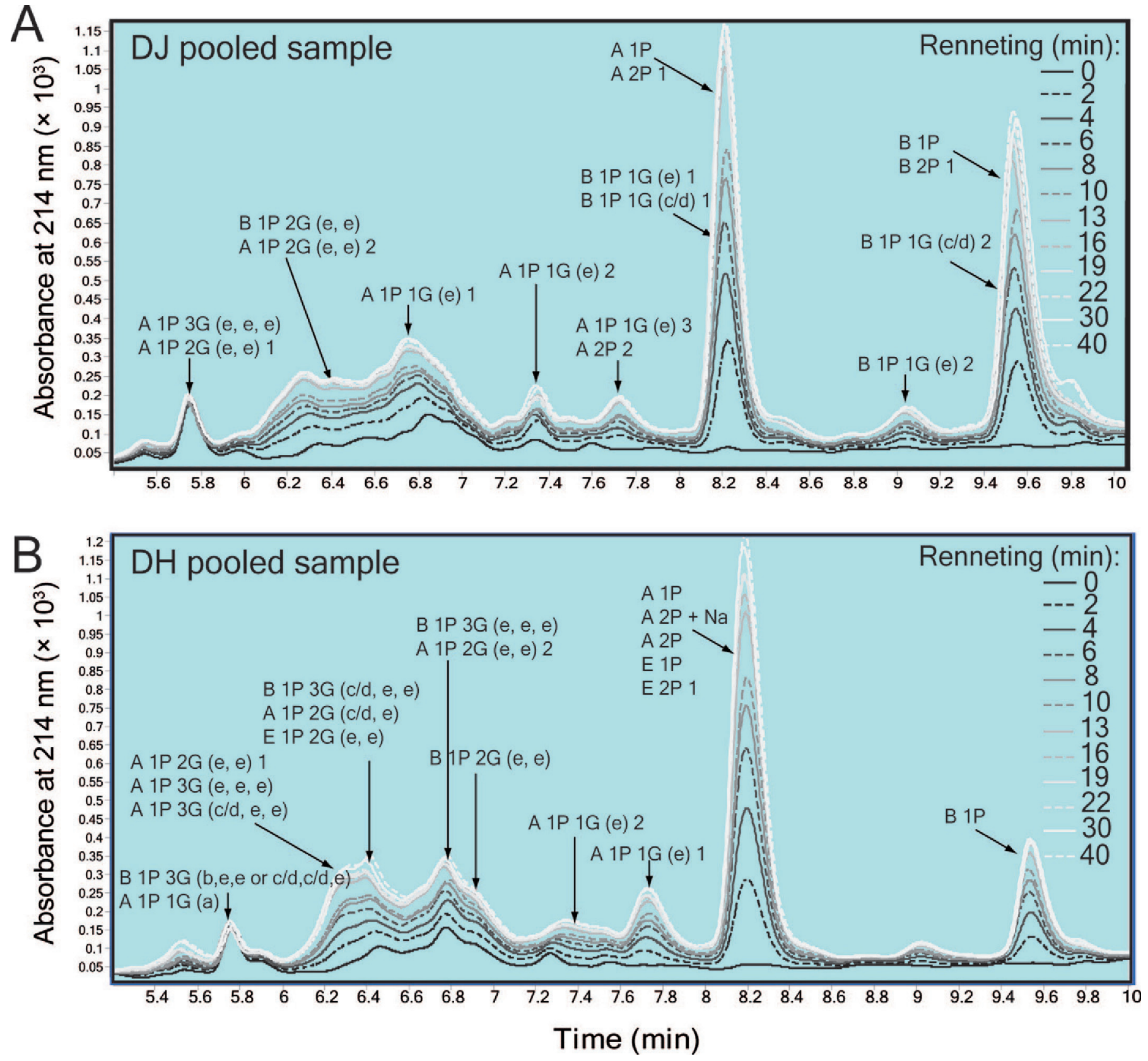

Figure 2. Chromatographic profile of caseino-macropeptide (CMP) isoform release in relation to renneting with chymosin (assessed from 0 to $40 \mathrm{~min}$ ); (A) Pooled Danish Jersey (DJ) sample, (B) Pooled Danish Holstein-Friesian (DH) sample. Name of the CMP isoforms refers to the CMP genetic variant (A, B, or E) with number of phosphate groups (1-2P), number of glycan groups (1-3G), glycosylation form (a, b, c, d, e; as described in the CMP Database subsection), and the last number indicates site of modification. Color version available online.

molecules, as the solubility of CMP depends on the degree of glycosylation.

To grasp the complexity of the CMP forms, the present study identified only the predominant PTM forms of CMP. In total, $21 \mathrm{CMP}$ isoforms in DJ and $26 \mathrm{CMP}$ isoforms in $\mathrm{DH}$ samples were identified, with $\mathrm{DH}$ milk containing an additional variant, $\kappa-\mathrm{CN} \mathrm{E}$, as explanatory for the overall higher CMP isoform variation. As expected, the chromatographic profile indicated similar retention times of CMP A and $\mathrm{E}$ due to similar protein hydrophobicities, whereas CMP B eluted later due to increased protein hydrophobicity. The identification of CMP isoforms was, to some extent, dependent of genetic variation, as a higher number of isoforms of CMP variant $\mathrm{A}$ was found compared with variant $\mathrm{B}$ and $\mathrm{E}$ (only DH). It is known that the primary structure of 
A

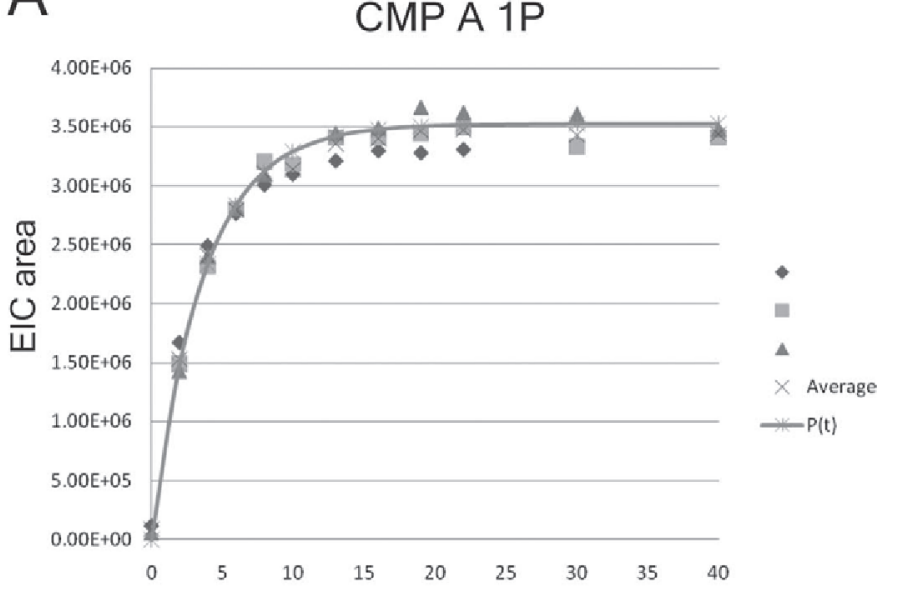

B

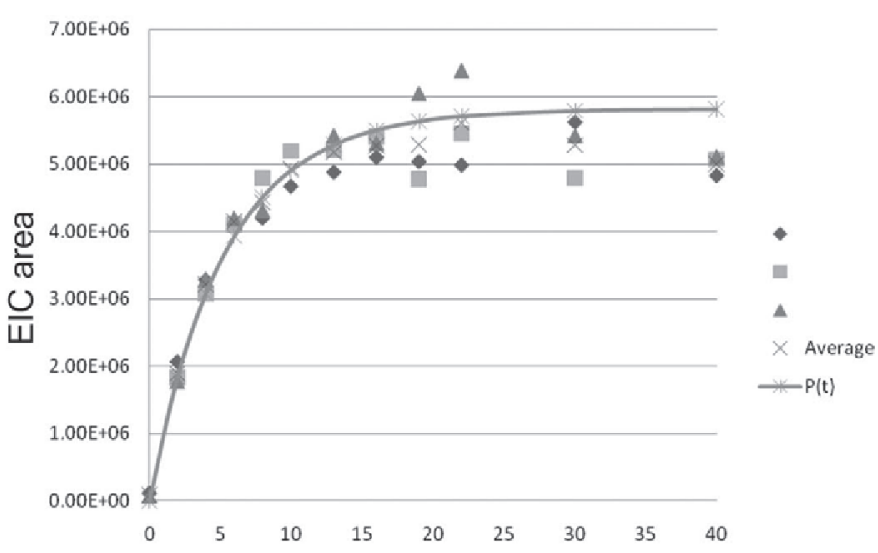

C

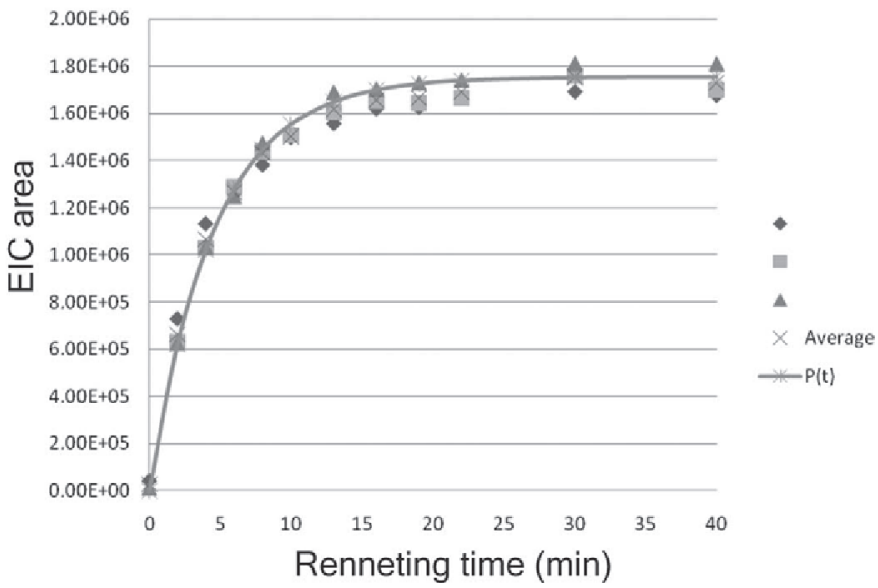

Figure 3. Direct nonlinear fit of CMP release in relation to time, $\mathrm{P}(\mathrm{t})$, estimated based on triplicate determinations of CMP formation during $40 \mathrm{~min}$ of renneting. Triplicates are denoted with symbols: $\diamond, \square, \Delta$. The major CMP isoforms (A, B, or E) in Danish HolsteinFriesian (DH) pooled milk are exemplified: (A) CMP A 1P, (B) CMP B $1 \mathrm{P}$ and (C) CMP E $1 \mathrm{P}$.
$\kappa-\mathrm{CN} \mathrm{A}$ and $\mathrm{E}$ contains an additional potential site of glycosylation compared with $\kappa-\mathrm{CN} \mathrm{B}$, as Thr is substituted with Ile at amino acid position 136. Although this site is not known as the major glycosylation site in $\kappa$-CN (Holland et al., 2005), it may still contribute to variation in PTM forms between genetic variants.

A merit of the applied proteomic approach elucidated the heterogeneity of the CMP isoforms to be uncovered, where the predominant CMP isoforms with $1-3 \mathrm{G}$ and 1-3P were identified as well as nonmodified isoforms, in agreement with other studies (Mollé and Léonil, 1995; Holland et al., 2005, 2006). The predominant phosphorylated forms of CMP were identified as the ones with $1-2 \mathrm{P}$, whereas forms with $3 \mathrm{P}$ were only identified in a limited number of DH samples. Increasing number of glycans attached to CMP increased the hydrophilicity and thereby decreased the retention time, in agreement with Brulé et al. (2000). The site of glycosylation was also found to influence the hydrophobicity and retention time, which made it possible to differentiate up to 3 sites per modified CMP isoform based on their distinct retention times within the chromatogram. As found in our study and in the study by Mollé and Léonil (1995), the c, d, and e glycosylation forms were the predominant CMP isoforms, whereas a and $\mathrm{b}$ forms were only identified in a limited number of DH samples.

The analytical approach employed for PTM analysis of $\kappa-\mathrm{CN}$ and CMP is of key importance. Previously, up to 3 phosphates and $9 \mathrm{NeuAc}$ residues have been detected in fractions of $\kappa$-CN separated by anion exchange chromatography, identifying at least $10 \kappa-\mathrm{CN}$ B isoforms (Vreeman et al., 1986). By means of 2-dimensional gels, 5 isoforms of both $\kappa-\mathrm{CN}$ variants $\mathrm{A}$ and $\mathrm{B}$ in milk from a single heterozygous cow have been identified (Holland et al., 2004), whereas using RPHPLC, 14 isoforms of the glyco-macropeptide in milk from a single $\kappa$-CN AA cow were discovered (Mollé and Léonil, 1995).

Furthermore, the present study brings novel knowledge about the cleavage rates for the distinct CMP forms representing different combinations of phosphorylated and glycosylated molecules in relation to $\kappa-\mathrm{CN}$ genetic variation. For the identified CMP isoforms in our study, the reaction rate constant of CMP release, $k$, was calculated as a measurement of CMP content during renneting with chymosin. The use of a formal kinetic fit eliminated the effect of the identified variation in the relative content between $\kappa-\mathrm{CN}$ genetic variants (as identified in Table 2). For both breeds, the CMP isoform with the highest reaction rate was CMP A $1-2 \mathrm{P}$, followed by CMP B 1-2P and by CMP E 1-2P (only DH milk). All of the identified glycosylated CMP isoforms had a lower reaction rate of CMP release than nonglycosylated CMP. This pointed toward a negative 

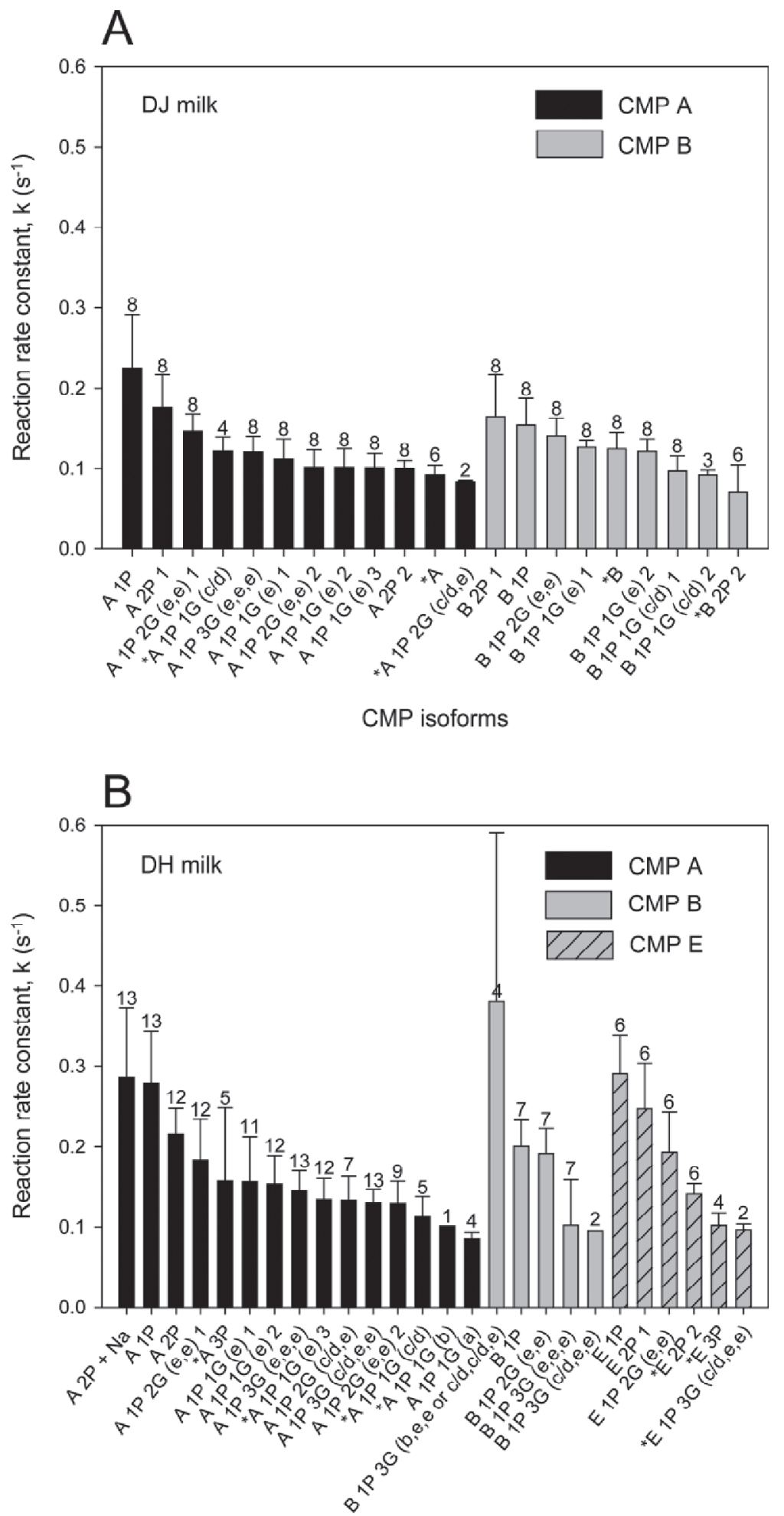

CMP isoforms

Figure 4. Reaction rate of caseino-macropeptide (CMP) release determined after 2 min of chymosin addition for the distinct CMP isoforms (mean $\pm \mathrm{SD}$ ) analyzed in milk from individual cows; (A) Danish Jersey (DJ), (B) Danish Holstein-Friesian (DH). The name of the CMP isoforms signifies the CMP genetic variant (A, B, or E) with number of phosphate groups (1-2 P), number of glycan groups (1-3 G), glycosylation forms ( $\mathrm{a}, \mathrm{b}, \mathrm{c}, \mathrm{d}$, e; as described in the CMP database subsection), and the last number indicates site of modification. An asterisk $\left({ }^{*}\right)$ indicates if the CMP isoform was identified only in the individual samples, not in pooled samples. Numbers on bars refer to the number of samples in which the CMP isoforms were identified. 
effect of glycosylation of $\kappa$ - $\mathrm{CN}$ for chymosin-induced hydrolysis compared with nonglycosylated forms.

A correlation between low cleavage rate and glycosylation of $\kappa-\mathrm{CN}$ has previously been supported by other authors (van Hooydonk et al., 1984; Ferron-Baumy et al., 1992). van Hooydonk et al. (1984) reported that increasing the carbohydrate content, and thus increasing the negative charge and hydrophilicity of $\kappa-\mathrm{CN}$, decreased the reaction between chymosin and $\kappa-\mathrm{CN}$, whereas cleavage was favored by low charge and low NeuAc acid content. Another study did not, however, estimate any differences in chymosin-induced cleavage of glycosylated and nonglycosylated $\kappa-\mathrm{CN}$ forms (Chaplin and Green, 1980). Furthermore, it has been proposed by several studies that the carbohydrate chains could hinder the access of chymosin to the cleavage site of $\kappa-\mathrm{CN}$, which will result in a decreased rate of reaction (Saito and Itoh, 1992; Dziuba and Minkiewicz, 1996; Brulé et al., 2000). In this regard, the specific site of PTM must be of key significance. The results of the present study give some indications that the specific PTM site on $\kappa$-CN may influence the cleavage rate by chymosin; CMP polypeptides with identical molecular composition but variation in the actual site of modification did not display similar rates of CMP generation. Similar reaction rates of CMP release could otherwise have been expected if the modification site was of no significance for the cleavage. It is also possible that the dissociation of CMP from the micellar complex after cleavage by chymosin varies with different PTM and contributes to the observed heterogeneity of CMP release between isoforms; this would require further study.

\section{CONCLUSIONS}

The present study provides novel knowledge regarding the release of various CMP isoforms during chymosininduced hydrolysis of distinct genotypes of $\kappa-\mathrm{CN}$ (AA, $\mathrm{BB}, \mathrm{AB}, \mathrm{EE}$, and $\mathrm{AE}$ ) in milk from 2 Danish dairy breeds. After $40 \mathrm{~min}$ of renneting, $>90 \%$ of intact $\kappa-\mathrm{CN}$ in both breeds was hydrolyzed by chymosin, releasing CMP into the whey fraction. In-depth analysis of the heterogeneity of CMP isoforms revealed isoforms with 1-3 G and 1-3 P, as well as nonmodified CMP isoforms. The kinetics of CMP release were followed by measurement of CMP content during renneting, and the highest reaction rate for all identified CMP isoforms occurred from 0 to 2 min of chymosin hydrolysis. Concurrent results from both breeds showed that glycosylated $\kappa-\mathrm{CN}$ isoforms had a lower reaction rate of CMP release compared with that of nonglycosylated CMP.

\section{ACKNOWLEDGMENTS}

The authors thank Arla Foods amba (Viby J, Denmark), The Danish Cattle Federation (Skejby, Denmark), the Danish Strategic Research Council (FøSu, Copenhagen, Denmark), and Aarhus University (Tjele, Denmark) for financial support through the project "Milk Genomics - Impact of genes for variation in milk composition and quality." Also, we owe special thanks to Valentin Rauh (Industrial $\mathrm{PhD}$ student at Arla Strategic Innovation Centre and Arhus University) for support in relation to protein kinetics.

\section{REFERENCES}

Bijl, E., R. de Vries, H. van Valenberg, T. Huppertz, and T. van Hooijdonk. 2014. Factors influencing casein micelle size in milk of individual cows: Genetic variants and glycosylation of $\kappa$-casein. Int. Dairy J. 34:135-141.

Bonfatti, V., G. Chiarot, and P. Carnier. 2014. Glycosylation of $\kappa$-casein: Genetic and nongenetic variation and effects on rennet coagulation properties of milk. J. Dairy Sci. 97:1961-1969.

Brulé, G., J. Lenoir, and F. Remeuf. 2000. The casein micelle and milk coagulation. Pages 7-40 in Cheesemaking from Science to Quality Assurance. A. Eck and J.-C. Gillis, ed. Lavoisier Publishing, Paris, France.

Caroli, A. M., S. Cheesa, and G. J. Erhardt. 2009. Invited review: Milk protein polymorphisms in cattle: Effect on animal breeding and human nutrition. J. Dairy Sci. 92:5335-5352.

Chaplin, B., and M. L. Green. 1980. Determination of the proportion of $\kappa$-casein hydrolysed by rennet on coagulation of skim-milk. J. Dairy Res. 47:351-358.

Coolbear, K. P., D. F. Elgar, and J. S. Ayers. 1996. Profiling and genetic variants of bovine $\kappa$-casein macropeptide by electrophoretic and chromatographic techniques. Int. Dairy J. 6:1055-1068.

Dalgleish, D. G. 1986. Analysis by fast protein liquid chromatography of variants of $\kappa$-casein and their relevance to micellar structure and renneting. J. Dairy Res. 53:43-51.

Dziuba, J., and P. Minkiewicz. 1996. Influence of glycosylation on micelle-stabilizing ability and biological properties of C-terminal fragments of cow's א-casein. Int. Dairy J. 6:1017-1044.

Ferron-Baumy, C., D. Mollé, G. Garric, and J. L. Maubois. 1992. Characterization of caseinomacropeptides released from renneted raw and UHT treated milks. Lait 72:165-173.

Frederiksen, P. D., K. K. Andersen, M. Hammershøj, H. D. Poulsen, J. Sørensen, M. Bakman, K. B. Qvist, and L. B. Larsen. 2011. Composition and effect of blending of noncoagulating, poorly coagulating, and well-coagulating bovine milk from individual Danish Holstein cows. J. Dairy Sci. 94:4787-4799.

Glantz, M., T. G. Devold, G. E. Vegarud, H. Månnson, Stålhammer, and M. Paulsson. 2010. Importance of casein micelle size and milk composition for milk gelation. J. Dairy Sci. 93:1444-1451.

Holland, J. W. 2009. Post-translational modifications of casein. Pages 107-132 in Milk Proteins: From Expression to Food. A. Thompson, M. Boland, and H. Singh, ed. Academic Press, Elsevier, San Diego, CA.

Holland, J. W., H. C. Deeth, and P. F. Alewood. 2004. Proteomic analysis of $\kappa$-casein microheterogeneity. Proteomics 4:743-752.

Holland, J. W., H. C. Deeth, and P. F. Alewood. 2005. Analysis of O-glycosylation site occupancy in bovine $\kappa$-casein glycoforms separated by two-dimensional gel electrophoresis. Proteomics 5:9901002.

Holland, J. W., H. C. Deeth, and P. F. Alewood. 2006. Resolution and characterisation of multiple isoforms of bovine $\kappa$-casein by $2-\mathrm{DE}$ following a reversible cysteine-tagging enrichment strategy. Proteomics 6:3087-3095. 
Ikonen, T., K. Ahlfors, R. Kempe, M. Ojaja, and O. Ruottinen. 1999 Genetic parameters for the coagulation properties and prevalence of noncoagulating milk in Finnish dairy cows. J. Dairy Sci. $82: 205-214$.

Jensen, H. B., J. W. Holland, N. A. Poulsen, and L. B. Larsen. 2012a. Milk protein variants and isoforms identified in bovine milk representing extreme in coagulation properties. J. Dairy Sci. 95:28912903.

Jensen, H. B., N. A. Poulsen, K. K. Andersen, M. Hammershøj, H. D. Poulsen, and L. B. Larsen. 2012b. Distinct composition of bovine milk from Jersey and Holstein-Friesian cows with good, poor, or noncoagulation properties as reflected in protein genetic variants and isoforms. J. Dairy Sci. 95:6905-6917.

Lieske, B., W. Faber, and G. Konrad. 1996. A new spectrophotometric approach for following the release of caseinomacropeptide during renneting of milk. Milchwissenschaft 51:548-551.

López, M. B., M. J. Jordan, P. Hellin, M. Castillo, and J. Laencina. 1997. Kinetics of $\kappa$-casein hydrolysis by different rennet and coagulant enzymes in Murciano-Granadina goat milk. Milchwissenschaft $52: 370-373$

Mollé, D., and J. Léonil. 1995. Heterogeneity of the bovine k-casein caseinomacropeptide, resolved by liquid chromatography on-line with electrospray ionization mass spectroscopy. J. Chromatogr. A. $708: 223-230$.

Poulsen, N. A., H. P. Bertelsen, H. B. Jensen, F. Gustavsson, M. Glantz, H. L. Månsson, A. Andrén, M. Paulsson, C. Bendixen, A. J. Buitenhuis, and L. B. Larsen. 2013. The occurrence of noncoagulating milk and the association of bovine milk coagulation properties with genetic variants of the caseins in 3 Scandinavian dairy breeds. J. Dairy Sci. 96:4830-4842.

Robitaille, G., K.-F. Ng-Kwai-Hang, and H. G. Monardes. 1991. Variation in the $\mathrm{N}$-acetyl neuraminic acid content of bovine $\kappa$-casein. J. Dairy Res. 58:107-114.

Saito, T., and T. Itoh. 1992. Variations and distribution of O-glycosidically linked sugar chains in bovine k-casein. J. Dairy Sci. 75:1768-1774.

Thomä, C., I. Krause, and U. Kulozik. 2006. Precipitation behaviour of caseinomacropeptides and their simultaneous determination with whey proteins by RF-HPLC. Int. Dairy J. 16:285-293.

Tyrisevä, A. M., K. Elo, A. Kuusipuro, V. Vilva, I. Jänönen, H. Karjalainen, T. Ikonen, and M. Ojala. 2008. Chromosomal regions underlying noncoagulation of milk in Finnish Ayrshire cows. Genetics 180:1211-1220.

van Hooydonk, A. C. M., C. Olieman, and H. G. Hagedoorn. 1984. Kinetics of the chymosin-catalysed proteolysis of $\kappa$-casein in milk. Neth. Milk Dairy J. 37:207-222.

Vreeman, H. J., S. Visser, C. J. Slangen, and J. A. M. Riel. 1986. Characterization of bovine $\kappa$-casein fractions and the kinetics of chymosin-induced macropeptide release from carbohydrate-free and carbohydrate-containing fractions determined by high-performance gel-permeation chromatography. Biochem. J. 240:87-97.

Wedholm, A., L. B. Larsen, H. Lindmark-Månsson, A. H. Karlsson, and A. Andrén. 2006. Effect of protein composition on the cheesemaking properties of milk from individual dairy cows. J. Dairy Sci. 89:3296-3305 